University of Wollongong

Research Online

Faculty of Engineering and Information

Faculty of Engineering and Information

Sciences - Papers: Part B

Sciences

2019

Experimental investigation on the mechanical and tribological coupled behaviour of bimetal composite under different states

Zhou Li

University of Wollongong, z|411@uowmail.edu.au

Jingwei Zhao

University of Wollongong, jzhao@uow.edu.au

Hui Wu

University of Wollongong, hwu@uow.edu.au

Fanghui Jia

University of Wollongong, fj910@uowmail.edu.au

Ye Yao

University of Wollongong, Shougang Research Institute of Technology, yyao@uow.edu.au

See next page for additional authors

Follow this and additional works at: https://ro.uow.edu.au/eispapers1

Part of the Engineering Commons, and the Science and Technology Studies Commons

Research Online is the open access institutional repository for the University of Wollongong. For further information contact the UOW Library: research-pubs@uow.edu.au 


\title{
Experimental investigation on the mechanical and tribological coupled behaviour of bimetal composite under different states
}

\begin{abstract}
Wear resistance and excellent mechanical properties are the main requirements in industrial applications of bimetal composites. The interfacial evolution of duplex stainless steel/low carbon steel (2205/AH36) bimetal composite after annealing and its tribological behaviour in a $3.5 \mathrm{wt} \% \mathrm{NaCl}$ solution were investigated in this study. The bonding interface evolution between two layers plays a critical role in mechanical properties of composite, and the surface microstructure of stainless steel layer determines the wear and corrosion resistance. The hot-rolled composite samples were heat treated at temperatures ranging from 850 to $1150{ }^{\circ} \mathrm{C}$ in steps of $100^{\circ} \mathrm{C}$ for $1 \mathrm{~h}$. Optical microscopy (OM) and electron backscattered diffraction (EBSD) were employed to investigate the microstructural evolution of both component layers and bonding interface. The uniaxial tensile tests were used to investigate the tensile strength and elongation of composites after annealing at different temperatures. Ball-on-disc sliding tests were employed to study the tribological behaviour of bimetal composite, with sample discs being immersed in the solution. The variations of the coefficient of friction (COF) were recorded as a function of the sliding time, and the wear tracks of discs after tribological tests were observed by the laser scanning microscope and a scanning electron microscope (SEM). The results show that the annealing temperature significantly affects the width of bonding interface, and the total wear volume loss of duplex stainless steel of composite is dominated by the mechanical wear in the chloride solution.

\section{Disciplines}

Engineering | Science and Technology Studies

\section{Publication Details}

Li, Z., Zhao, J., Wu, H., Jia, F., Yao, Y., Zhang, Q., Jiao, S. \& Jiang, Z. (2019). Experimental investigation on the mechanical and tribological coupled behaviour of bimetal composite under different states. Surface Topography: Metrology and Properties, 7 (2), 025015-1-025015-14.
\end{abstract}

\section{Authors}

Zhou Li, Jingwei Zhao, Hui Wu, Fanghui Jia, Ye Yao, Qingfeng Zhang, Sihai Jiao, and Zhengyi Jiang 


\title{
Experimental investigation on the mechanical and tribological coupled behaviour of bimetal composite under different states
}

\author{
Zhou $\mathrm{Li}^{1}$, Jingwei Zhao ${ }^{1}$, Hui Wu ${ }^{1}$, Fanghui $\mathrm{Jia}^{1}$, Ye Yao ${ }^{1,3}$, Qingfeng Zhang ${ }^{2}$, Sihai Jiao ${ }^{2}$ and \\ Zhengyi Jiang $^{1 *}$ \\ ${ }^{1}$ School of Mechanical, Materials, Mechatronic and Biomedical Engineering, University of Wollongong, \\ Wollongong, NSW 2522, Australia \\ ${ }^{2}$ Baosteel Research Institute (R\&D Centre), Baoshan Iron \& Steel Co., Ltd., Shanghai 200431, China \\ ${ }^{3}$ Shougang Research Institute of Technology, Beijing 100043, China
}

Keywords: Tribological behaviour; 3.5 wt. \% NaCl solution; Bimetal composite; Annealing

Abstract. Wear resistance and excellent mechanical properties are the main requirements in industrial applications of bimetal composites. The interfacial evolution of duplex stainless steel/low carbon steel (2205/AH36) bimetal composite after annealing and its tribological behaviour in a 3.5 wt. \% $\mathrm{NaCl}$ solution were investigated in this study. The bonding interface evolution between two layers plays a dominated role in mechanical properties of composite, and the surface microstructure of stainless steel layer determines the wear and corrosion resistance. The hot-rolled composite samples were heat treated at temperatures ranging from 850 to $1150{ }^{\circ} \mathrm{C}$ in steps of $100{ }^{\circ} \mathrm{C}$ for $1 \mathrm{~h}$. Optical microscopy (OM) and electron backscattered diffraction (EBSD) were employed to investigate the microstructural evolution of both component layers and bonding interface. The uniaxial tensile tests were used to investigate the tensile strength and elongation of composites after annealing at different temperatures. An Rtec MFT-5000 Multi-functional Tribometer was employed to study the tribological behaviour of bimetal composite using ball-on-disc sliding tests, with sample discs being immersed in the solution. The variations of the coefficient of friction (COF) were recorded as a function of the sliding time. The wear tracks of discs after tribological tests were examined under a VK-X100 laser scanning microscope and observed by a scanning electron microscope (SEM). The results show that the annealing temperature significantly affects the width of bonding interface, and the total wear volume loss of duplex stainless steel of composite is dominated by the mechanical wear in the chloride solution.

\section{Declaration of conflicting interests}

The authors declare that there is no conflict of interest.

*Corresponding author: +61 2 42214545, jiang@uow.edu.au. 


\section{Introduction}

With the increasing demand for the multi-functionality but low cost of engineering materials, bimetal and laminated composites, which combine high wear resistance and excellent mechanical properties, have become popular for applications in many industrial fields, including pressure vessels, pipelines and mining equipment [1-4]. Among the composite materials, stainless steel laminate composites, such as stainless steel/carbon steel [5-7], aluminum/ferritic stainless steel [8], magnesium/aluminum/ferritic stainless steel [9], and austenitic stainless steel/aluminum/copper [10], are the most widely produced and used.

In order to eliminate defects from the combination processing of different materials, post-processing techniques are often required to improve the performance of bimetal composites. There are a number of researchers who have studied the effects of heat treatments on the mechanical performance of composites [11, 12]. Bina et al. [13] reported that the tensile strength and elongation of stainless steel/copper bimetal plate increased after post heat treatments. He et al. [14] found that the strength and flow stress of multi-layered zirconium/titanium composites increased gradually with the increase of annealing temperature and time in compressive tests. Macwan et al. [15] identified the influence of post-rolling annealing on the interface microstructure and mechanical properties of aluminium/magnesium/aluminium tri-metal plates. They presented that the ultimate tensile strength reached the maximum at $250{ }^{\circ} \mathrm{C}$ while the elongation increased with the increase of annealing temperature. Zhang et al. [16] obtained the similar results for magnesium (AZ31B)/aluminium (6061) composite, in which the yield and tensile strengths reached the highest at $200{ }^{\circ} \mathrm{C}$ due to the elimination of dislocations and residual stresses between two bonded layers in the annealing process.

Alternatively, some other researchers investigated the influences of heat treatments on the tribological behaviour of various stainless steels. Wang et al. [17] found that the best wear resistance of 316L stainless steel could be achieved after annealing at $750{ }^{\circ} \mathrm{C}$ for $20 \mathrm{~min}$, corresponding to a moderate hardness rather than the highest hardness of annealed samples. Yin et al. [18] investigated the corrosive wear behaviour of annealed AISI 1045 steel in the $3.5 \mathrm{wt}$ \% $\mathrm{NaCl}$ solution under different loads at room temperature by using the scratch test, and they concluded that corrosive wear rates were markedly affected by the loading speed and force. Davanageri et al. [19] and Fargas et al. [20] indicated that the existence of sigma phase $(\sigma)$ increased the hardness and wear resistance of the heattreated super duplex stainless steel AISI 2507.

However, there has been little information available so far on the influence of annealing on the mechanical and tribological coupled behaviour of bimetal composites. In general, the higher hardness 
of metals and alloys is required for better wear resistance in industrial applications, but with less toughness and plasticity. It is, therefore, necessary to consider both the wear corrosion resistance and formability of composites to achieve a balance that meets various industrial requirements. The aim of this study is to investigate the mechanical and tribological coupled properties of duplex stainless steel/low carbon steel (2205/AH36) bimetal composite over the temperature range from 850 to $1150{ }^{\circ} \mathrm{C}$ in steps of $100{ }^{\circ} \mathrm{C}$ with the annealing time of $1 \mathrm{~h}$. Uniaxial tensile tests and sliding ball-on-disc tests with samples being immersed in a $3.5 \mathrm{wt}$. \% $\mathrm{NaCl}$ solution were carried out, respectively, to evaluate the tensile strength, elongation and corrosive wear resistance of bimetal composite. The optimal annealing conditions were proposed considering both the duplex stainless steel and the carbon steel, which can simultaneously satisfy the combination of good formability and enhanced wear resistance in the chloride solution.

\section{Methodology and materials}

A duplex stainless steel bimetal composite plate, consisting of the duplex ferritic $(\alpha)$-austenitic $(\gamma)$ stainless steel (2205) layer with the thickness of $3 \mathrm{~mm}$ and the carbon steel (AH36) layer with the thickness of $8 \mathrm{~mm}$, was produced by a hot-rolling process using commercially available products in this study, as shown in Fig. 1. The chemical compositions of 2205 and AH36 are shown in Table 1.

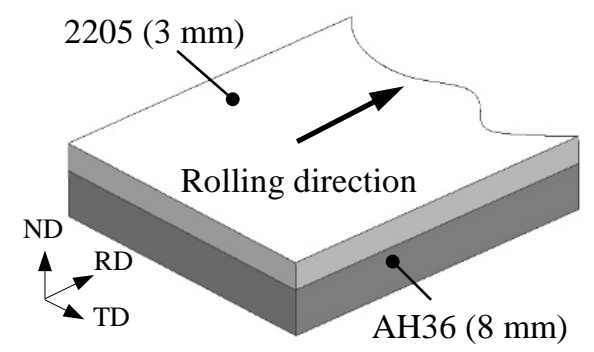

Fig. 1. Schematic illustration of the bimetal composite plate.

Table 1 Chemical compositions of bonded components (wt. \%).

\begin{tabular}{llllllllll}
\hline Materials & $\mathrm{C}$ & $\mathrm{Si}$ & $\mathrm{Mn}$ & $\mathrm{P}$ & $\mathrm{S}$ & $\mathrm{Cr}$ & $\mathrm{Mo}$ & $\mathrm{Ni}$ & $\mathrm{Fe}$ \\
\hline 2205 & 0.024 & 0.62 & 1.4 & 0.023 & 0.001 & 21.07 & 3.01 & 5.36 & $\mathrm{Bal}$ \\
AH36 & 0.18 & 0.50 & $0.90-1.60$ & 0.035 & 0.035 & 0.20 & 0.08 & 0.40 & $\mathrm{Bal}$ \\
\hline
\end{tabular}

Tensile specimens, consisting of the 2205 layer ( $3 \mathrm{~mm}$ ) and the AH36 layer ( $3 \mathrm{~mm}$ ), were cut by a Spark Erosion Cutting (SEC). The dimensions of tensile specimens are shown in Fig. 2. Uniaxial tensile tests were performed on a universal testing machine Instron-8801 with crosshead speed of 1.5 $\mathrm{mm} / \mathrm{min}$, and the measured gauge length is $25 \mathrm{~mm}$, according to ASTM E8/E8M. The tribological tests were carried out using an Rtec MFT-5000 Multi-functional Tribometer [21-23], and the configuration of the ball-on-disc tribometer is shown in Fig. 3. 


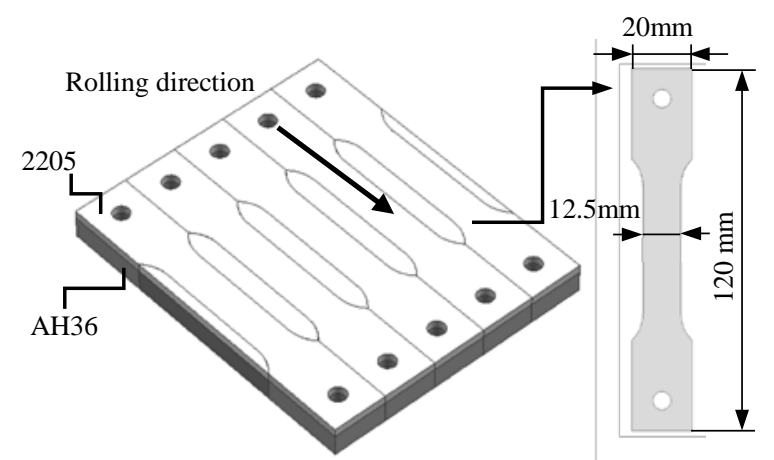

Fig. 2. Dimensions of bimetal specimens.

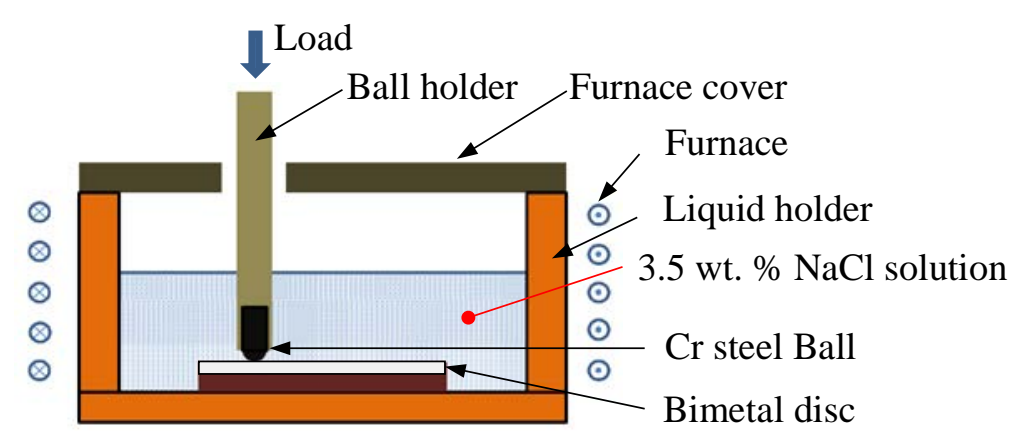

Fig. 3. Schematic illustration of ball-on-disc test.

All the discs were machined to $50 \mathrm{~mm}$ in diameter and $6 \mathrm{~mm}$ in thickness, consisting of the 2205 layer and the AH36 layer, each of which has a thickness of $3 \mathrm{~mm}$. The disc surfaces were ground to be uniform with a roughness $\left(\mathrm{R}_{\mathrm{a}}\right)$ of around $0.04 \mu \mathrm{m}$. During the sliding tests, only the 2205 layer surface of bimetal disc was rotating against the stationary $\mathrm{Cr}$ steel ball, and the whole disc was immersed in the $3.5 \mathrm{wt}$ \% NaCl solution, as an electrolyte simulating the corrosive marine and mining environment, to evaluate the effect of chloride on the tribological behaviour of composites in nature. The applied Cr steel ball has a diameter of $9.5 \mathrm{~mm}$ with a hardness of $780 \mathrm{HV}$. The bimetal discs were loaded with a normal force of $80 \mathrm{~N}$ and a linear speed of $20 \mathrm{~mm} / \mathrm{s}$ for $2 \mathrm{~h}$. All the tribological tests were performed open to air at $65^{\circ} \mathrm{C}$, which is higher than the critical pitting temperature (CPT), for the applied 2205 layer [24-26], in order to create a harsh test environment. The wear tracks of discs after the tribological test were cleaned in the ultrasonic ethanol bath for $6 \mathrm{~min}$. All the tensile and tribological tests were repeated 3 times for each sample. Prior to the tensile and tribological sliding tests, the tensile specimens and disc samples were placed in an electric furnace at 850, 950, 1050 and $1150{ }^{\circ} \mathrm{C}$ for $1 \mathrm{~h}$, respectively, under the protection of argon, and then cooled down naturally in the furnace to the room temperature (Fig. 4). 


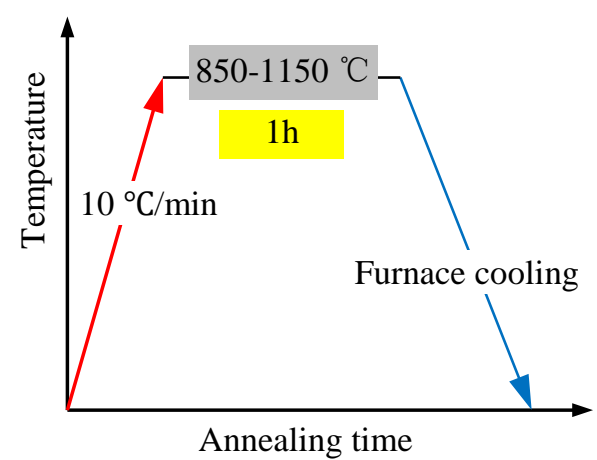

Fig. 4. Schematic illustration of the annealing process.

Conventional Vickers hardness tests for the 2505 layer of discs were conducted with a load of $9.8 \mathrm{~N}$ for $10 \mathrm{~s}$ after annealing treatments. The microstructure of the rolling direction-normal direction (RDND) section planes after annealing was examined by an optical microscopy (OM), for which the section planes were mechanically ground to $0.25 \mu \mathrm{m}$ followed by etching with a solution of $50 \mathrm{ml}$ $\mathrm{HCl}+50 \mathrm{ml} \mathrm{HNO}_{3}+50 \mathrm{ml} \mathrm{H}_{2} \mathrm{O}$. The microstructural characterisation of the 2205 layer after annealing treatment was conducted under a JEOL 7001 electron backscattered diffraction (EBSD). A KEYENCE VK-X100 3D laser scanning microscope and a JSM-6490F scanning electron microscope (SEM) equipped with an energy dispersion spectrometer (EDS) were used to observe the morphology and EDS mappings of wear tracks produced on the discs.

\section{Results and discussion}

\subsection{Microstructural evolution}
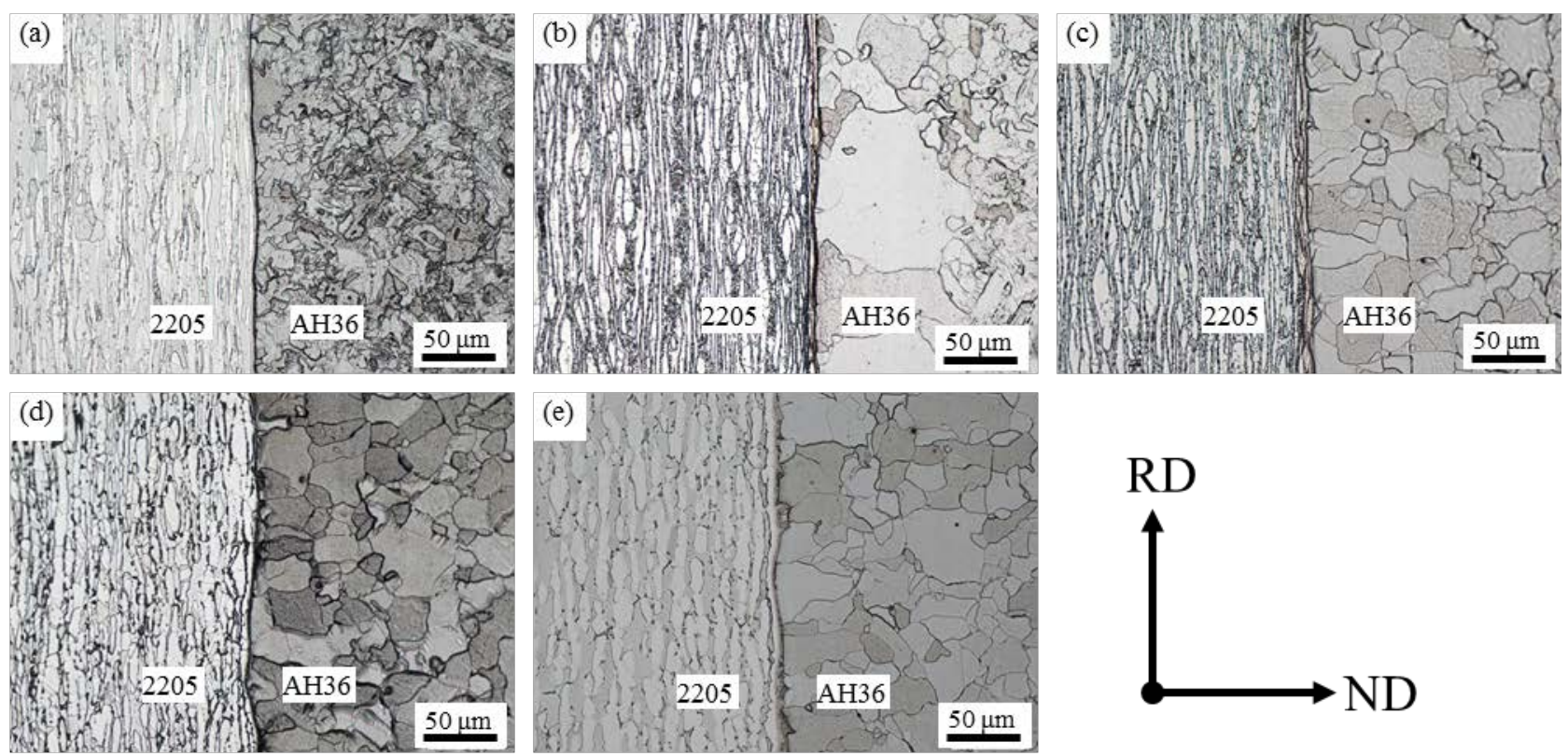

Fig. 5. Optical microstructures of the bond interface under different states: (a) as-received, (b) annealed at $850{ }^{\circ} \mathrm{C}$, (c) annealed at $950{ }^{\circ} \mathrm{C}$, (d) annealed at $1050{ }^{\circ} \mathrm{C}$, and (e) annealed at $1150{ }^{\circ} \mathrm{C}$. 
The microstructure of the RD-ND section planes of the as-received specimen, as well as those heattreated at 850, 950, 1050 and $1150{ }^{\circ} \mathrm{C}$ are presented in Fig. 5. The left section, composed of alternating ferrite and austenite bands, is the duplex stainless steel (2205). The right section, in contrast, consisting of the acicular or polygonal ferrite, is the low carbon steel (AH36). The microstructural evolution of AH36 between the as-received and annealed specimens varies significantly, i.e. the ferrite grains have become polygonal shape after annealing treatments. In particular, the ferrite grains adjacent to the bonding interface are coarsening after annealing at $850{ }^{\circ} \mathrm{C}$, which may have a negative influence on the elongation [27]. With the increase of annealing temperature to 950 and $1050{ }^{\circ} \mathrm{C}$, the ferrite grains are uniformly distributed in the matrix of AH36, but the ferrite grain size slightly increases when the temperature further rises to $1150{ }^{\circ} \mathrm{C}$.
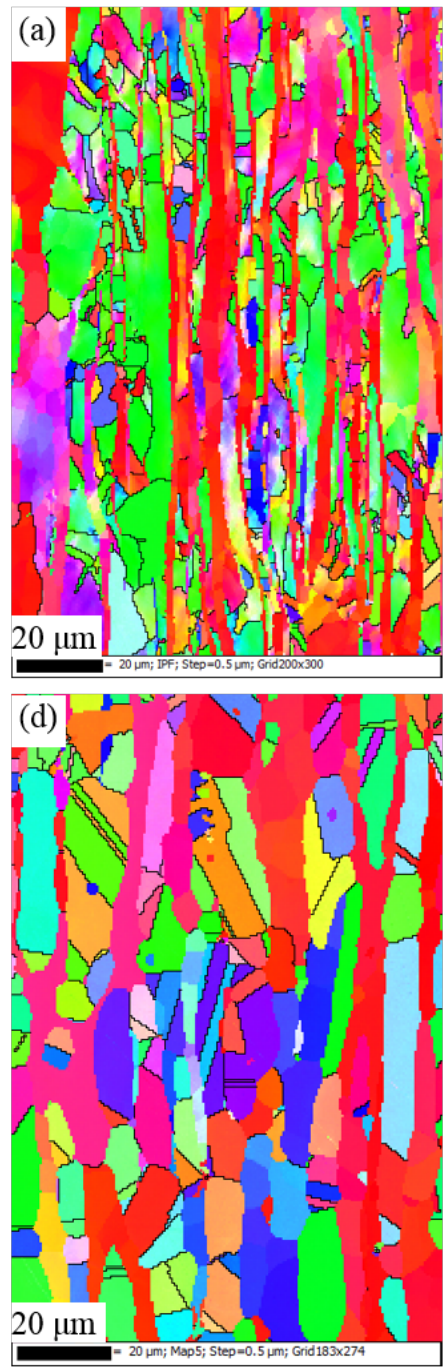
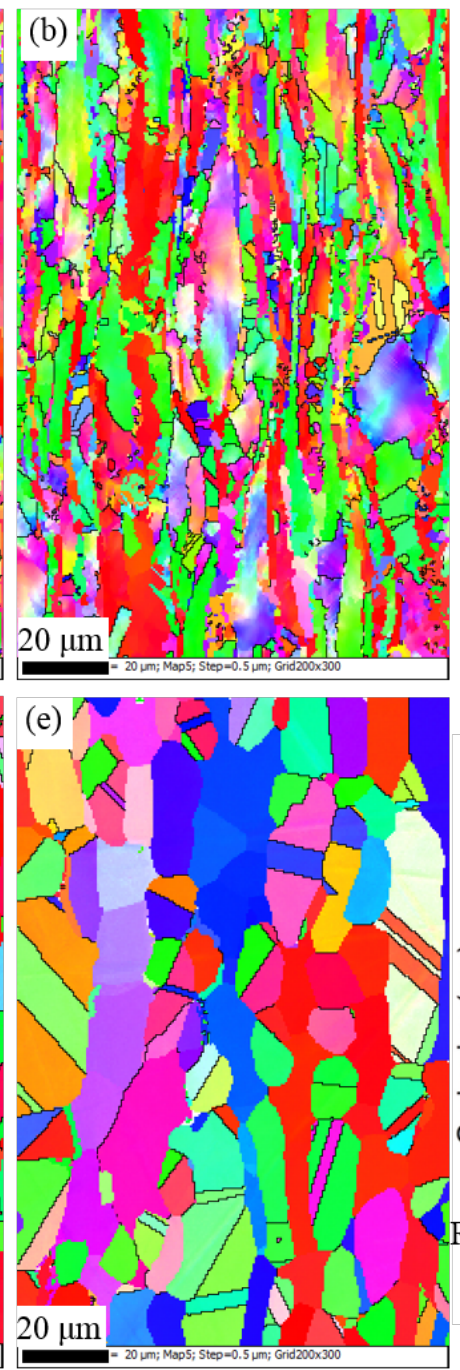
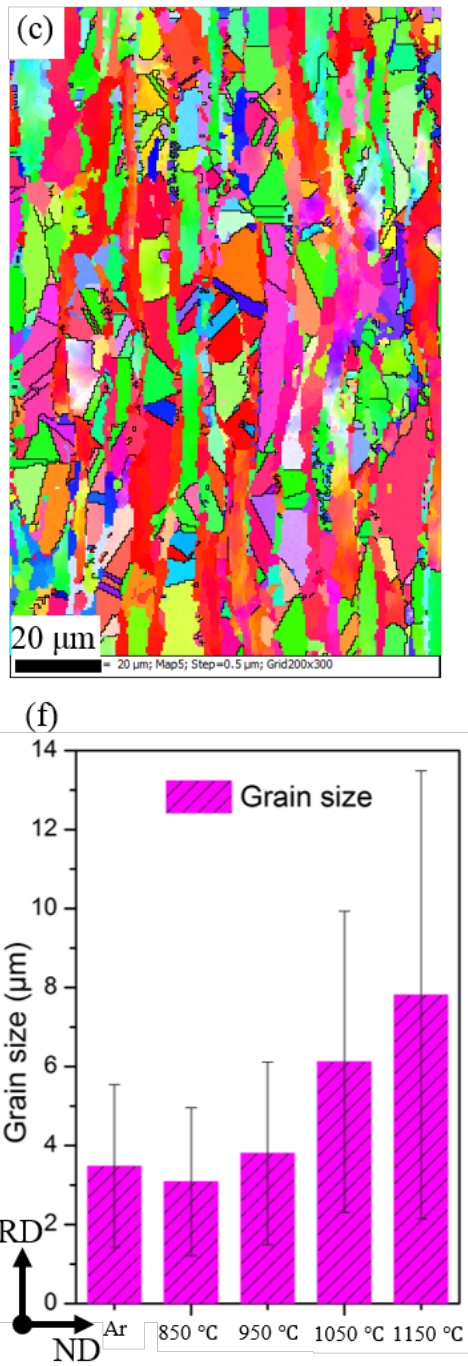

Fig. 6. IPF map of the 2205 layer from EBSD under different states: (a) as-received, (b) annealed at $850^{\circ} \mathrm{C}$, (c) annealed at $950^{\circ} \mathrm{C}$, (d) annealed at $1050^{\circ} \mathrm{C}$, (e) annealed at $1150{ }^{\circ} \mathrm{C}$, and (f) comparison of grain size. 
After annealing treatments, the microstructure of the 2205 layer remains markedly oriented along the RD under each state, but the wavy morphology of ferrite begins to disappear, and thicker bands of austenite and ferrite appear at 1050 and $1150{ }^{\circ} \mathrm{C}$, consistent with the results of Reference [28]. The grain size of the 2205 layer begins to increase from 950 to $1150{ }^{\circ} \mathrm{C}$, and this trend is proved by the IPF map from EBSD, as shown in Fig. 6. The grain size of the 2205 layer achieves to the largest at $1150^{\circ} \mathrm{C}$ (Fig. 6(f)).

Additionally, the annealing treatment has an influence on the microstructural evolution of metallurgical bonding transition zone (MBTZ) adjacent to the interface formed in the composite bonding process, which is a main difference between the bimetal composite and single material. The evolution of interfacial properties (e.g. the bonding strength and toughness), mainly resulting from the element diffusion behaviour between layers, affects the total mechanical characterisations of composites (e.g. the tensile strength and elongation) [29-31]. The most difference of chemical compositions between the 2205 and AH36 contains C, Cr, Fe, Mo and Ni etc. elements. The concentration difference of these elements causes the element diffusion between two layers during the post annealing processes of composite. In Fig. 7, it can be seen that the diffusion profiles of elements ( $\mathrm{Cr}$ and $\mathrm{Fe}$ ) in the MBTZ are different for the as-received specimen, and the annealed specimens at $850,950,1050$ and $1150{ }^{\circ} \mathrm{C}$. As the 2205 layer is rich in Cr elements, which have a close atomic size compared to that of iron atoms, the $\mathrm{Cr}$ and Fe atoms can exchange between the 2205 and AH36 layers by the direct exchange mechanism, resulting in the formation of MBTZ. The approximate thickness comparison of MBTZ under different annealing conditions is shown in Fig. $7(\mathrm{k})$. It is obvious that that the thickness of the interfacial diffusion zone increases with the rise of annealing temperature, and the thickness of MBTZ with the annealing time follows the parabolic rule, expressed as [15, 32]:

$$
x=\sqrt{D t}
$$

where $x$ is the diffusion distance (i.e. the thickness of MBTZ), $t$ is the annealing time, and $D$ is the inter-diffusion coefficient, which is determined by Arrhenius equation [15]:

$$
D=D_{0} \exp \left(-\frac{Q}{R T}\right)
$$

where $D_{0}$ is the frequency factor, $Q$ is the activation energy for the diffusion, $R$ is the gas constant (8.3145 $\mathrm{J} \mathrm{mol}^{-1} \mathrm{~K}^{-1}$ ), and $T$ is the absolute temperature $(\mathrm{K})$.

Then, the relationship between the thickness of MBTZ, annealing temperature and time can be denoted as: 


$$
x=\sqrt{D_{0} \exp \left(-\frac{Q}{R T}\right) t}
$$

It is noted that the square of the thickness of MBTZ increases linearly with annealing time, while it increases exponentially with the annealing temperature. Therefore, the influence of annealing temperature on the thickness of MBTZ is far more than that of annealing time, which can explain why the thickness evolution of MBTZ increases with the increase of annealing temperature.
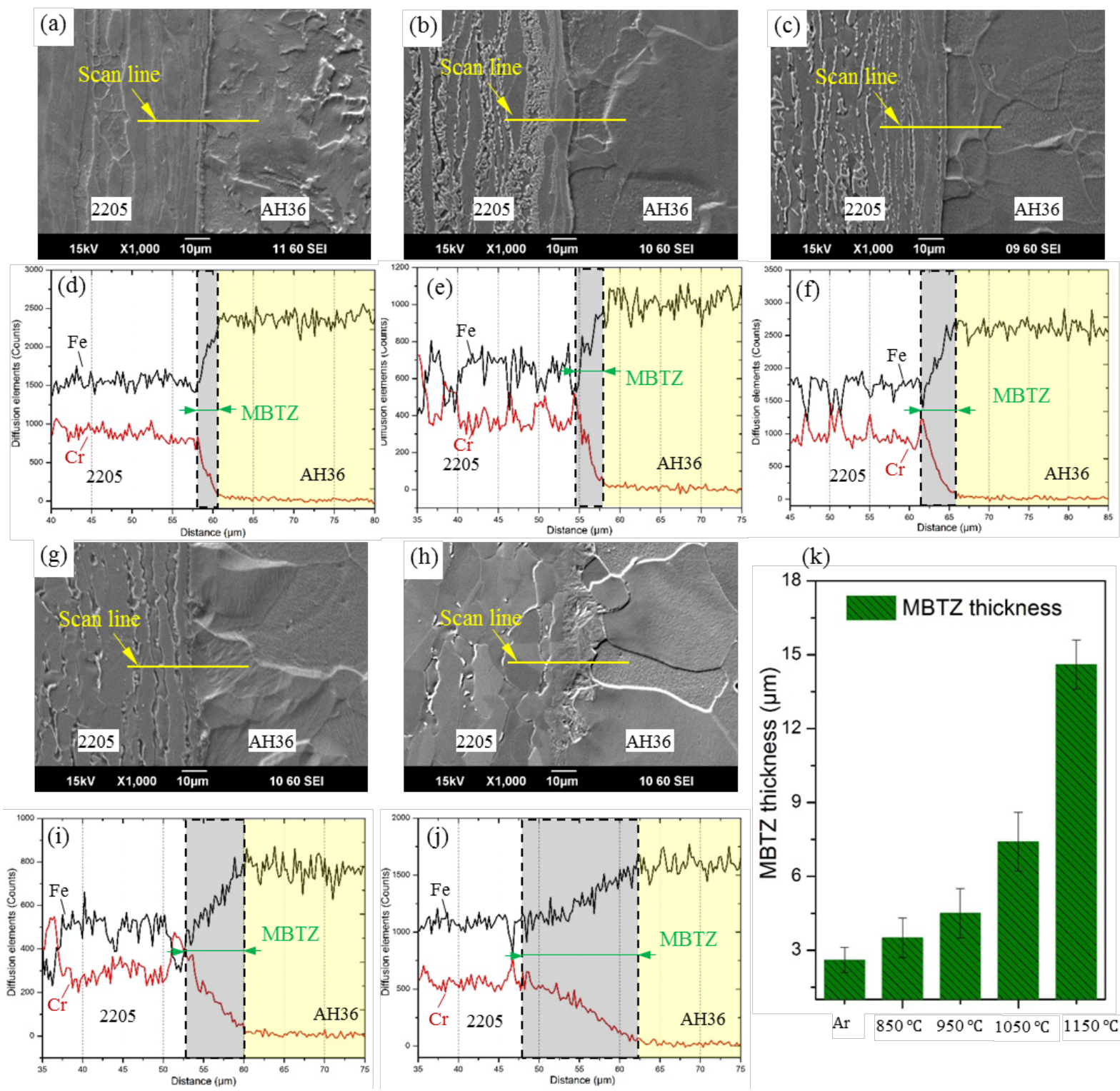

Fig. 7. SEM morphologies and diffusion profiles of elements in the MBTZ under different states: (a, d) as-received, (b, e) annealed at $850{ }^{\circ} \mathrm{C}$, (c, f) annealed at $950{ }^{\circ} \mathrm{C},(\mathrm{d}, \mathrm{g})$ annealed at $1050{ }^{\circ} \mathrm{C},(\mathrm{h}, \mathrm{j})$ annealed at $1150^{\circ} \mathrm{C}$, and $(\mathrm{k})$ comparison of MBTZ thickness.

\subsection{Mechanical performance}

The changes in tensile strength and elongation with the annealing temperatures are shown in Fig. 8. It can be noted that the elongation, determining the plasticity and formability of bimetal composites, 
is sensitively dependent on the annealing temperatures. The elongation value decreases from $15.02 \%$ to $12.15 \%$ after annealing at $850{ }^{\circ} \mathrm{C}$, indicating that the formability of bimetal composites after this annealing process may exhibit a certain decline. The elongation of bimetal specimens, however, increases gradually after annealing from 950 to $1150{ }^{\circ} \mathrm{C}$, and the elongation is higher than that of the as-received state after annealing at 1050 and $1150{ }^{\circ} \mathrm{C}$. Meanwhile, the composite specimens after annealing at temperatures from 950 to $1150{ }^{\circ} \mathrm{C}$ exhibit a slight decrease in the tensile strength, and this trend is the opposite of grain size changes shown in Fig. 6(f). It agrees with the Hall-Petch strengthening, in which smaller grains with more grain boundaries can act as pinning points, impeding the propagation of dislocations [33].

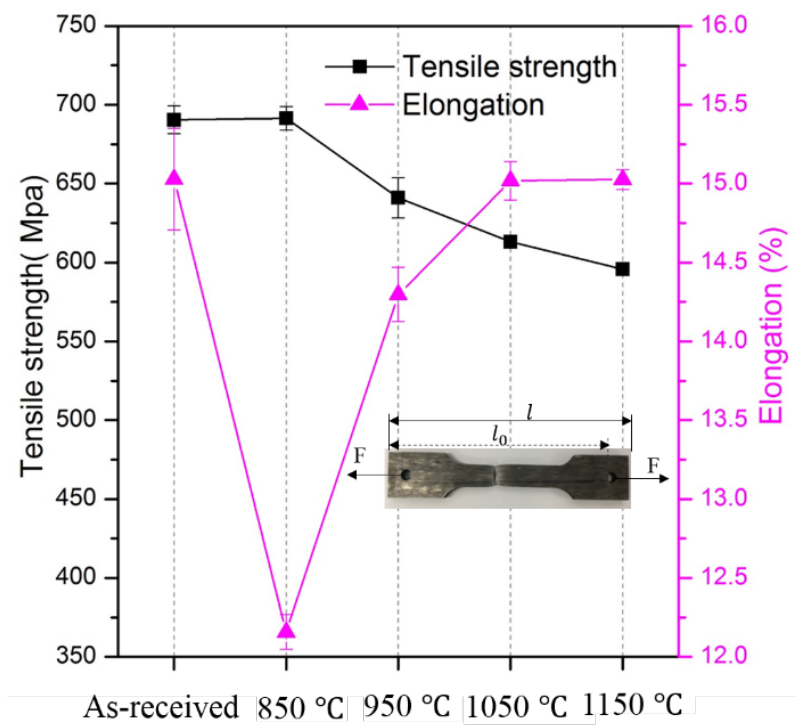

Fig. 8. The effect of annealing temperature on the tensile strength and elongation.

Fig. 9 shows the tensile profile and frontal fracture characteristics of bimetal composite after annealing at different temperatures. In the as-received, and annealed at 1050 and $1150{ }^{\circ} \mathrm{C}$ states, the obvious delamination occurs in MBTZ between 2205 and AH36 layers, but the composite shows good overall toughness and plasticity. In contrast, the fracture sections of tensile specimens, after annealing at 850 and $950{ }^{\circ} \mathrm{C}$, are relatively flat, and the two layers of composite are simultaneously broken without delamination crack in MBTZ, exhibiting a certain overall brittleness. This result is consistent with the trend of the elongation values in Fig. 8. In addition, the thickness values of MBTZ are higher after annealing at 1050 and $1150{ }^{\circ} \mathrm{C}$ than that of other states, which may easily trigger the delamination crack in the MBTZ adjacent to the interface [5]. 


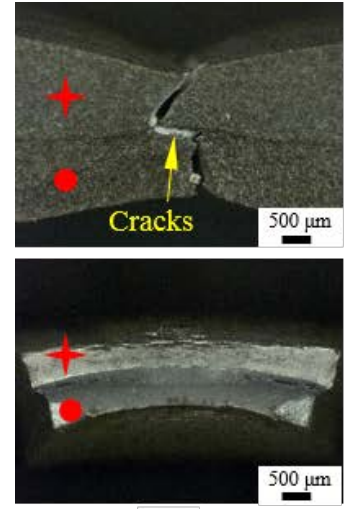

(a)
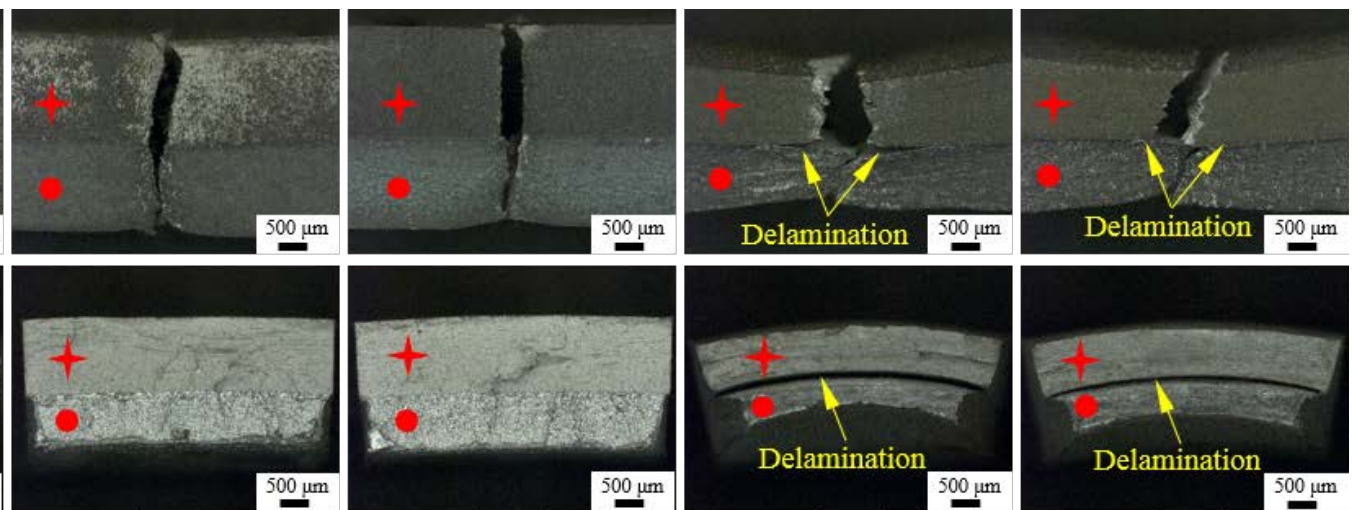

(b)

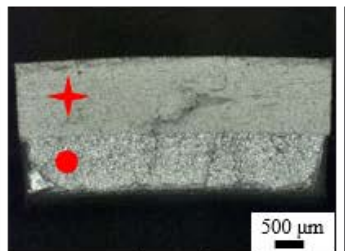

(c)

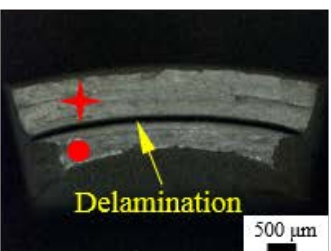

(d)

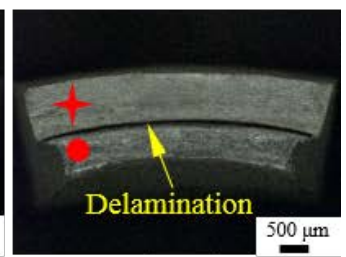

(e)

Fig. 9. The tensile profile and frontal fracture characteristics under different states: (a) as-received, (b) annealed at $850{ }^{\circ} \mathrm{C}$, (c) annealed at $950{ }^{\circ} \mathrm{C}$, (d) annealed at $1050{ }^{\circ} \mathrm{C}$, and (e) annealed at $1150{ }^{\circ} \mathrm{C}$.

\subsection{COF and wear volume loss}

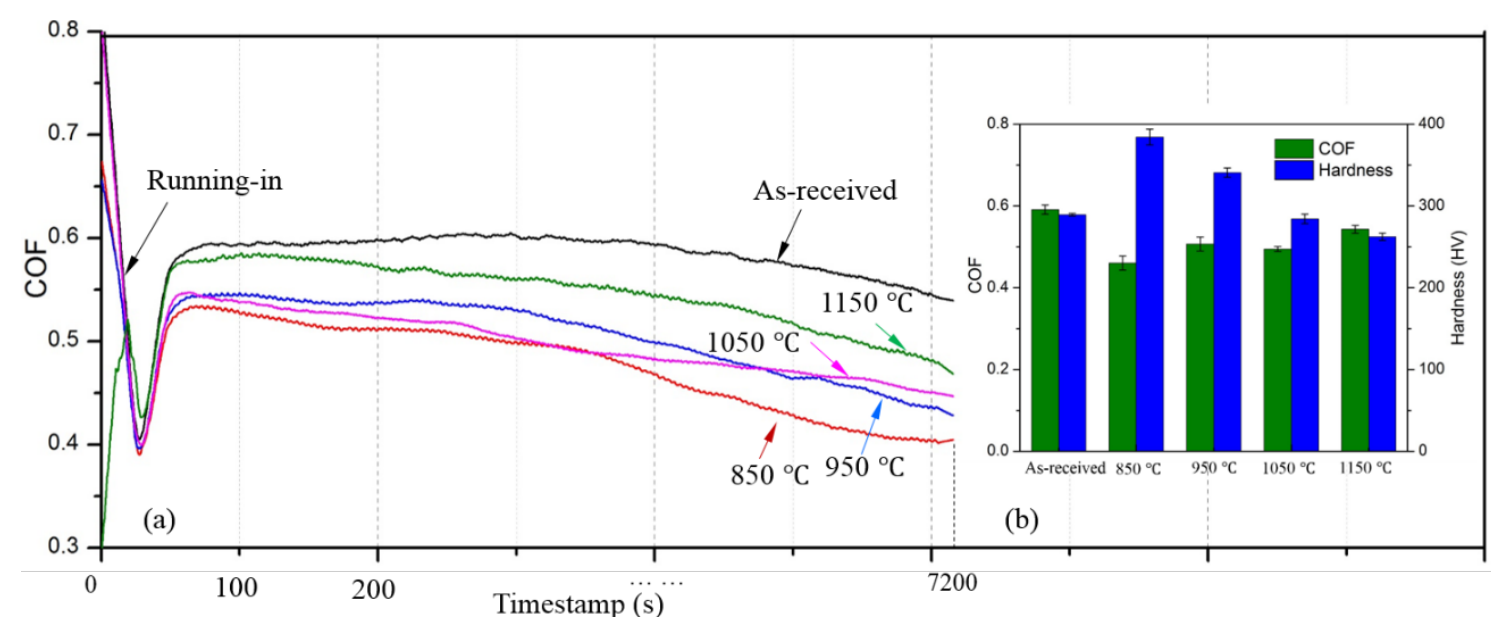

Fig. 10. (a) In-situ COFs, and (b) comparison of COFs and hardness measured under different states in the $3.5 \mathrm{wt}$ \% $\mathrm{NaCl}$ solution.

Fig. 10(a) presents the in-situ COF curves of samples annealed at different temperatures in the 3.5 wt. \% $\mathrm{NaCl}$ solution, from which the $\mathrm{COF}$ curves are found to fluctuate severely in the running-in period but show a stable trend in the remaining process [34, 35]. The mean COF values obtained from the stable stages for the as-received disc, and the annealed discs at 850, 950, 1050 and $1150{ }^{\circ} \mathrm{C}$ are 0.59, 0.46, 0.50, 0.49 and 0.54, respectively. The COF value reaches the smallest after annealing at $850{ }^{\circ} \mathrm{C}$, as shown in Fig. 10(b). In contrast, the hardness value of the disc surface presents a notable increase from 289.3 (as-received state) to $384.3 \mathrm{HV}$ after annealing at $850{ }^{\circ} \mathrm{C}$. The hardness values, however, decrease gradually from $850{ }^{\circ} \mathrm{C}$ to $1150{ }^{\circ} \mathrm{C}$. The $\mathrm{COF}$ value changes inversely proportional to the hardness values. One reason is that the hard surface can minimise the plastic deformation, which brings about a decrease in the ability of metals to adhere. Another reason is that relatively 
harder metals have a higher surface energy, which induces the requirement of higher work for adhesion [36, 37].

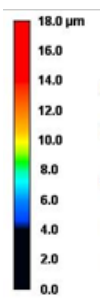

(a) Wear area: $860 \mu \mathrm{m}^{2}$
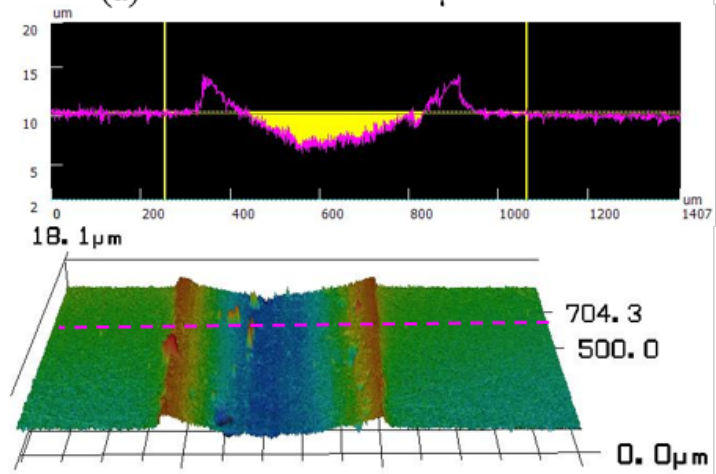

1408. $0 \quad 1000.0 \quad 500.0$

$0.0 \mu \mathrm{m}$

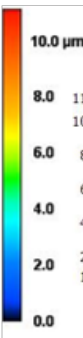

(c) Wear area: $610 \mu \mathrm{m}^{2}$
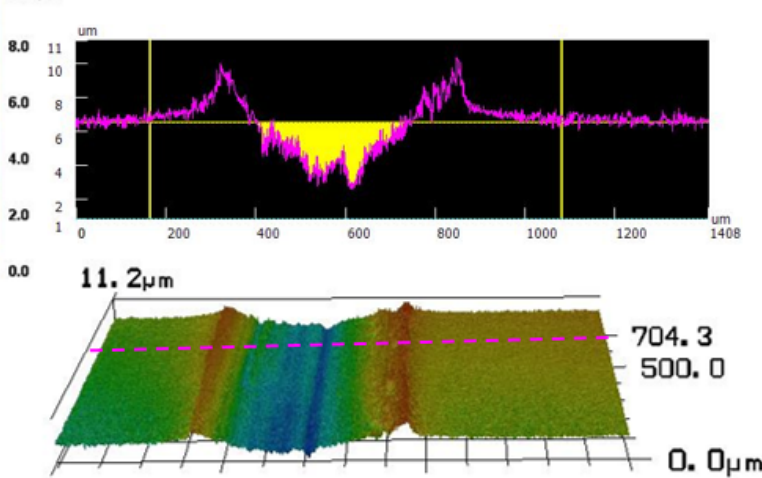
1408. 7 1000. 0
500. 0
0. $0 \mu \mathrm{m}$

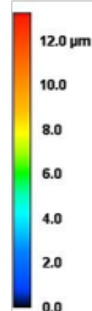

(e) Wear area: $1138 \mu \mathrm{m}^{2}$

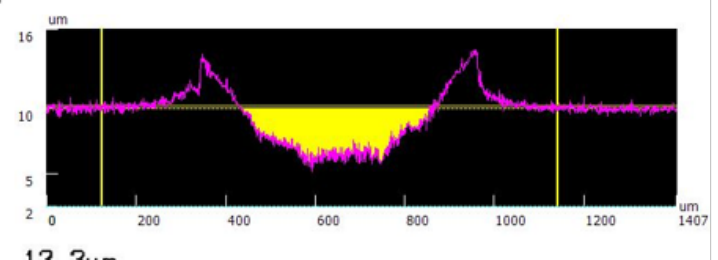

13. $3 \mu \mathrm{m}$

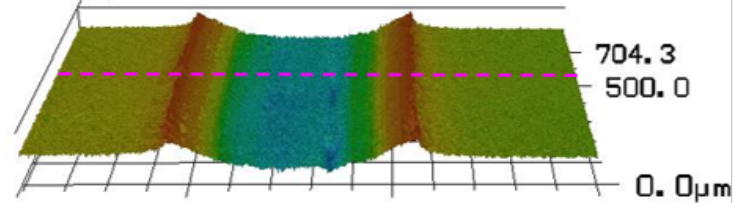

1408. 0 1000. 0

0. $0 \mu \mathrm{m}$

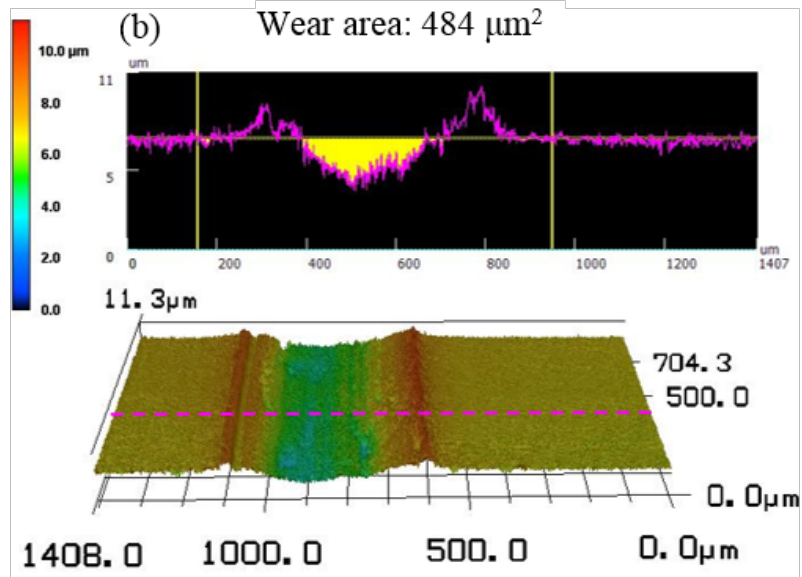

(d) Wear area: $786 \mu \mathrm{m}^{2}$
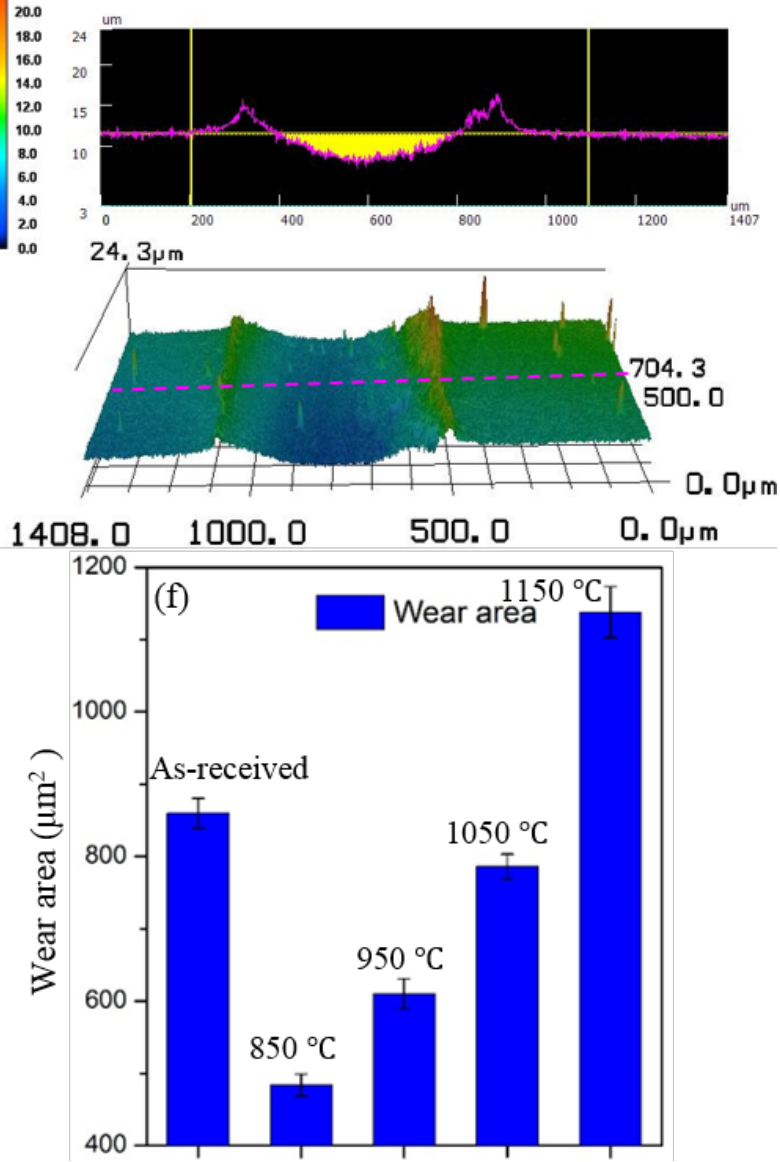

Fig. 11. 3D profile images and curves of disc wear tracks under different states: (a) as-received, (b) annealed at $850^{\circ} \mathrm{C}$, (c) annealed at $950{ }^{\circ} \mathrm{C}$, (d) annealed at $1050{ }^{\circ} \mathrm{C}$, (e) annealed at $1150{ }^{\circ} \mathrm{C}$, and (f) comparison of wear volume loss.

The three-dimensional (3D) laser microscopy was commonly used to characterise the wear surfaces [38-41]. The 3D profile of wear tracks after tribological tests in the $3.5 \mathrm{wt}$. $\% \mathrm{NaCl}$ solution are shown in Fig. 11. The total wear volume loss is an essential measurement to determine the degradation of 
the duplex stainless steel (2205), and it can be calculated by the wear area of the track profile, which is used to characterise the wear volume in this study. It is clear that the wear area of the as-received disc is $860 \mu \mathrm{m}^{2}$ along the depth direction which is higher than that of the discs annealed at 850, 950 and $1050{ }^{\circ} \mathrm{C}$, respectively. The lowest wear volume occurs in the disc annealed at $850{ }^{\circ} \mathrm{C}$, while the wear area values are rising continuously with the increase of annealing temperatures from 850 to $1150{ }^{\circ} \mathrm{C}$, as shown in Fig. 11(f). This is related to their hardness values after annealing at higher temperatures (Fig. 10(b)), since softer steel surfaces are more sensible to the repeated shear stresses from the sliding wear, which leads to micro-cracks and consequently the wear volume loss [42].
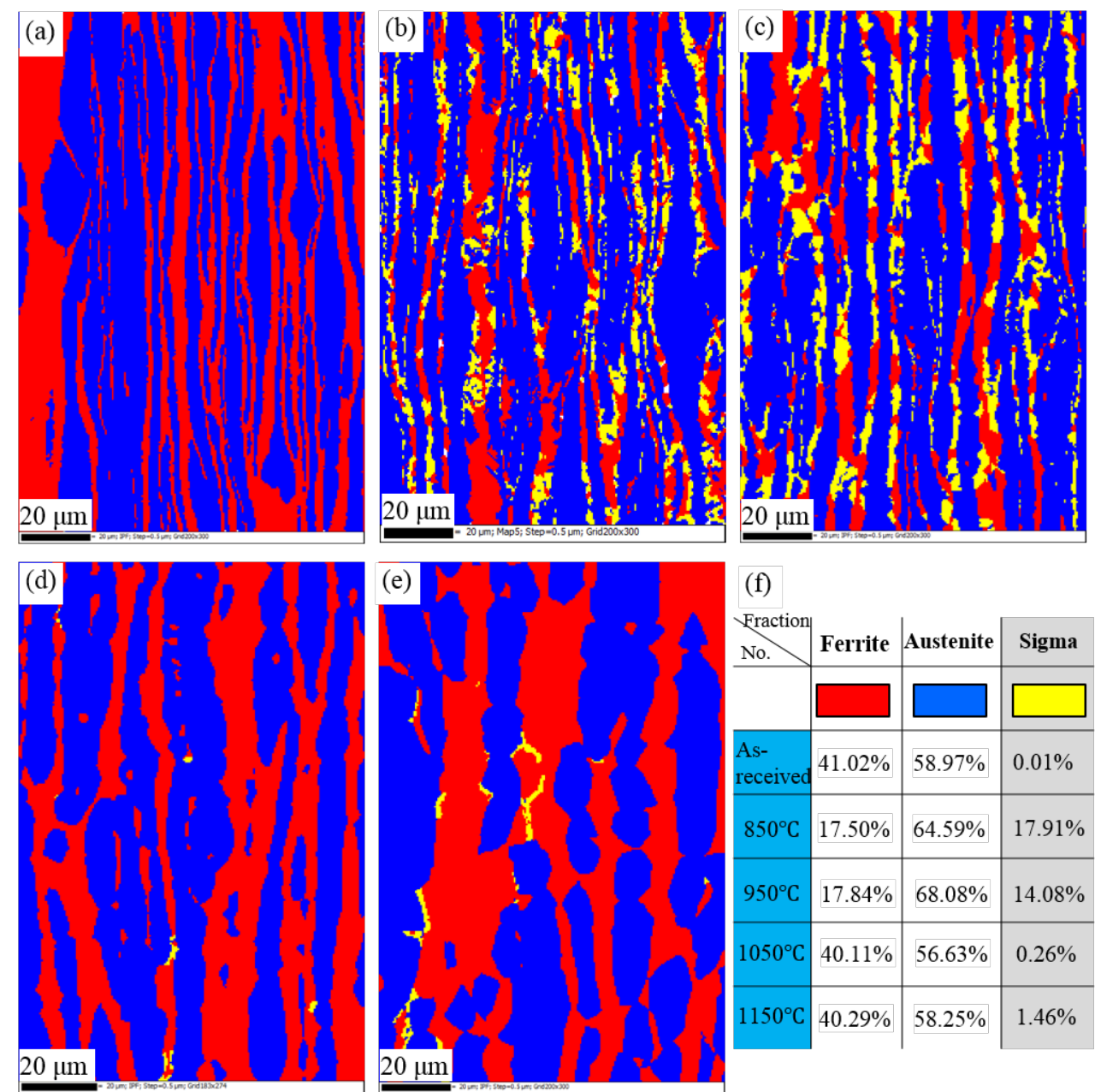

Fig. 12. Phase map obtained by EBSD under different states: (a) as-received, (b) annealed at $850{ }^{\circ} \mathrm{C}$, (c) annealed at $950{ }^{\circ} \mathrm{C}$, (d) annealed at $1050{ }^{\circ} \mathrm{C}$, (e) annealed at $1150{ }^{\circ} \mathrm{C}$, and (f) partition fraction of each phase. Moreover, the wear volume loss in the tribological tests is significantly determined by the microstructure of the 2205 layer after annealing treatments, especially affected by the precipitation of the sigma phase and volume fractions of ferrite and austenite. Fig. 12 shows the phase map and volume fractions of the ferrite, austenite and sigma phases obtained by EBSD under different states. In Figs. 12(b), 12(c) and 12(e), it can be seen that the sigma phase mainly nucleates at the interface 
of ferrite/austenite phase and grows into the adjacent ferrite grains via an eutectoid reaction, inducing the decomposition of ferrite into an aggregate of sigma and secondary austenite [28]. In Fig. 12(f), the volume fractions of precipitated sigma phase are relatively high after annealing at 850 and $950{ }^{\circ} \mathrm{C}$, reaching to $17.91 \%$ and $14.08 \%$, respectively, but the sigma phase almost dissolves at the annealing temperature of $1050^{\circ} \mathrm{C}$. The precipitation of Cr- and Mo-rich sigma phase results in the deterioration of plastic and corrosion resistance, which has been presented previously [24, 43, 44] and agrees with the results in Section 3.2. Due to the precipitation of sigma phase after annealing at 850 and $950{ }^{\circ} \mathrm{C}$, however, the hardness values of the discs increase greatly. Meanwhile, the hard sigma phase is embedded as pinning particles in the soft austenite phase, resulting in the improvement of the wear resistance of discs in the chloride solution, which can be improved by the trend of the wear area in Fig. 11(f).

In addition to the effect of sigma phase, the volume fraction of austenite phase can also influence the wear volume during the tribological test. It is easier for the austenite phase to induce the surface deformation strengthening in the wear tracks, especially under high loads [45], which consequently leads to increased hardness and improved corrosive wear resistance. The hardness values of seven positions were measured on the wear track and adjacent area after sliding tests for discs annealed at 850 and $1050{ }^{\circ} \mathrm{C}$, respectively, as shown in Fig. 13. It can be seen that the hardness values of the wear track increase significantly by $40.9 \%$ and $67.9 \%$ at 850 and $1050{ }^{\circ} \mathrm{C}$, respectively, as compared to that of unworn areas of the discs.

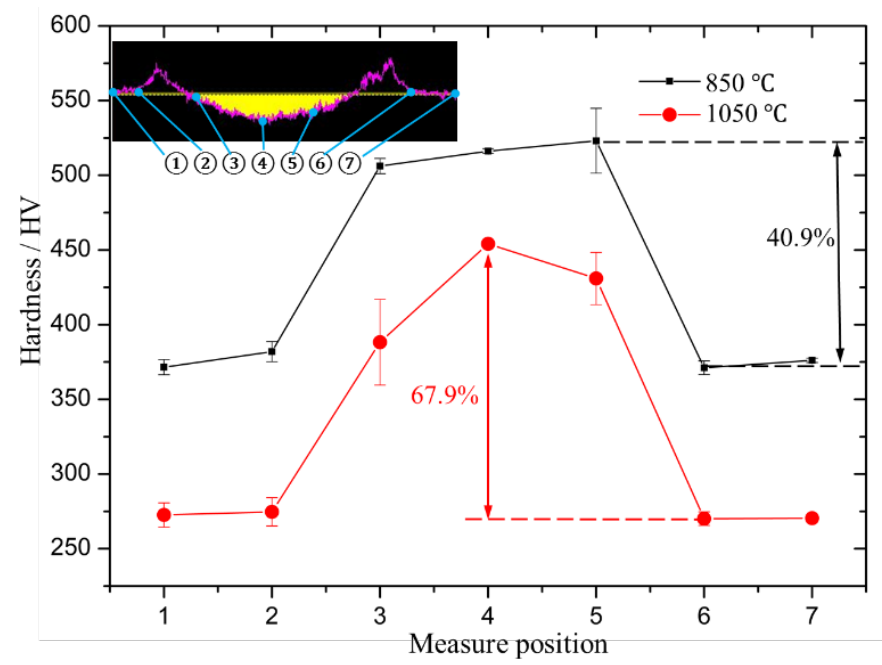

Fig. 13. The variations of hardness of the wear track and adjacent area at 850 and $1050{ }^{\circ} \mathrm{C}$.

\subsection{Surface morphology}

Fig. 14 shows the morphology of wear tracks under different states after tribological tests in the 3.5 wt. \% $\mathrm{NaCl}$ solution. Although the width values of the wear tracks are different, the wear tracks have similar morphological features for the as-received and annealed discs. Many longitudinal grooves in 
the sliding direction (SD) caused by the asperities of the hard ball counter-face are the predominant feature in the wear tracks, indicating that the abrasive wear is the main tribological mechanism. Large oxidised bands covering the most areas of the wear tracks are obvious, and the presence of numerous pits can be observed in the wear tracks under all the states. It is also worth noting that ridges form on the edge of all wear tracks (Fig. 11), which indicates that the large plastic flow, including surface and subsurface plastic shear, has occurred. As a result, the adhesive wear of detached material also exists during the tribological tests in the chloride solution. Fig. 15 shows the macro-worn surface of Cr steel balls after tribological tests under different states, the wear morphologies of the ball tips are similar. The worn area of ball tip is largest after annealing at $1150{ }^{\circ} \mathrm{C}$, which agrees with the wear volume loss in Fig. 11(f).
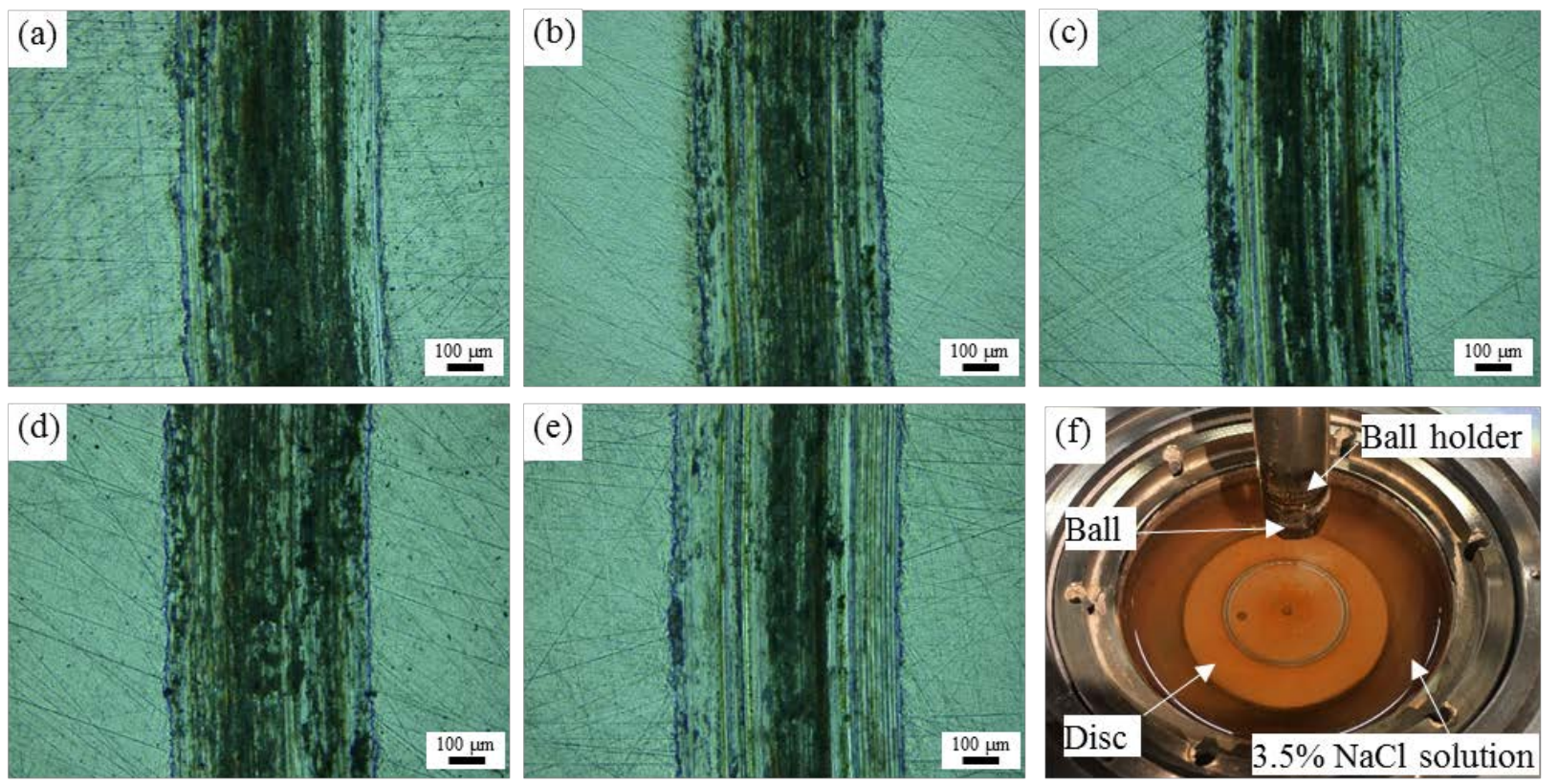

Fig. 14. Wear tracks on discs under different states: (a) as-received, (b) annealed at $850{ }^{\circ} \mathrm{C}$, (c) annealed at $950{ }^{\circ} \mathrm{C}$, (d) annealed at $1050{ }^{\circ} \mathrm{C}$, (e) annealed at $1150{ }^{\circ} \mathrm{C}$, and (f) a disc in the liquid holder.

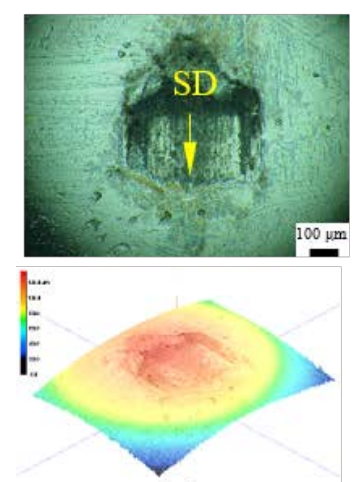

(a)

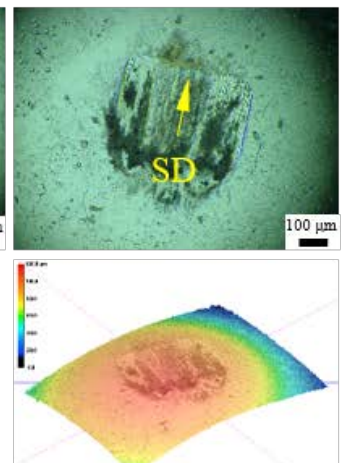

(b)

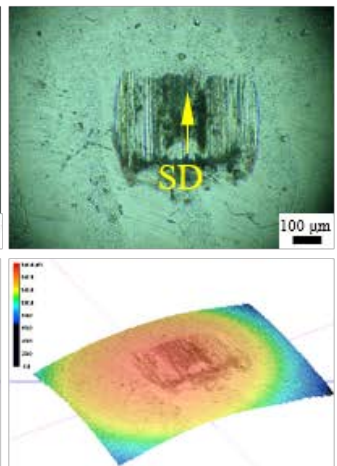

(c)

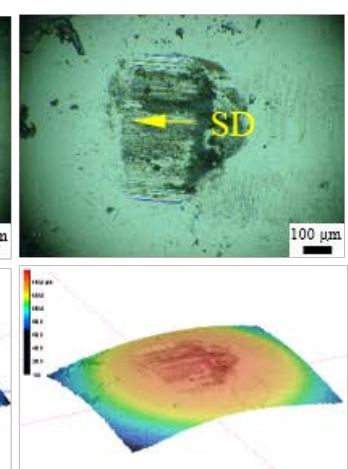

(d)

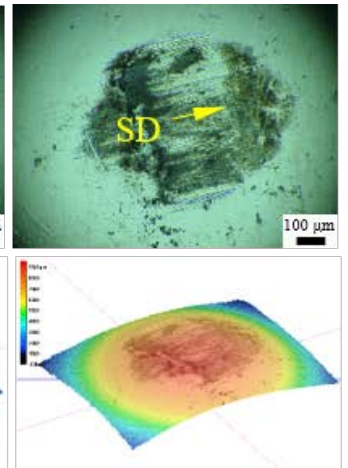

(e)

Fig. 15. Worn surfaces of balls under different states: (a) as-received, (b) annealed at $850{ }^{\circ} \mathrm{C}$, (c) annealed at $950{ }^{\circ} \mathrm{C}$, (d) annealed at $1050{ }^{\circ} \mathrm{C}$, and (e) annealed at $1150{ }^{\circ} \mathrm{C}$. 
The SEM morphologies of worn surface obtained under different states are shown in Fig. 16. A large amount of crack networks can be observed on the oxidised bands of corrosive worn surfaces under all states. When the cracks grow large enough, the spalling and flaking, and as a consequence the loss of material from the sliding surface may emerge [20]. It means that the 2205 layer is suffered from both the mechanical wear and the corrosion. In addition, the oxidised bands and cracks are thick under the as-received state, but the oxidised bands are more dispersed and evenly distributed on the worn surface after annealing treatments.
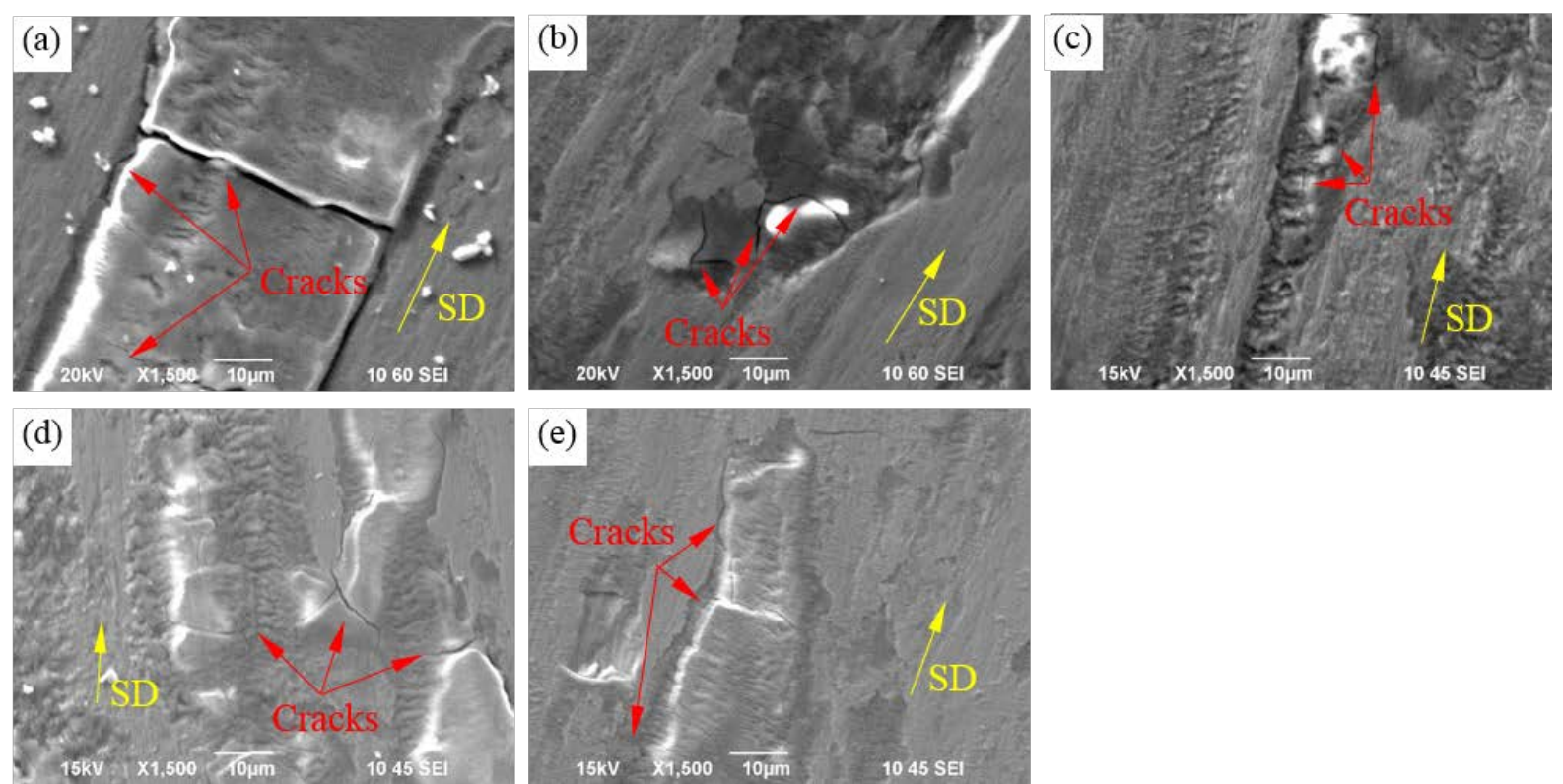

Fig. 16 SEM morphologies of worn surface obtained under different states: (a) as-received, (b) annealed at $850{ }^{\circ} \mathrm{C}$, (c) annealed at $950{ }^{\circ} \mathrm{C}$, (d) annealed at $1050{ }^{\circ} \mathrm{C}$, and (e) annealed at $1150{ }^{\circ} \mathrm{C}$.

\subsection{Tribological mechanism in the $\mathrm{NaCl}$ solution}

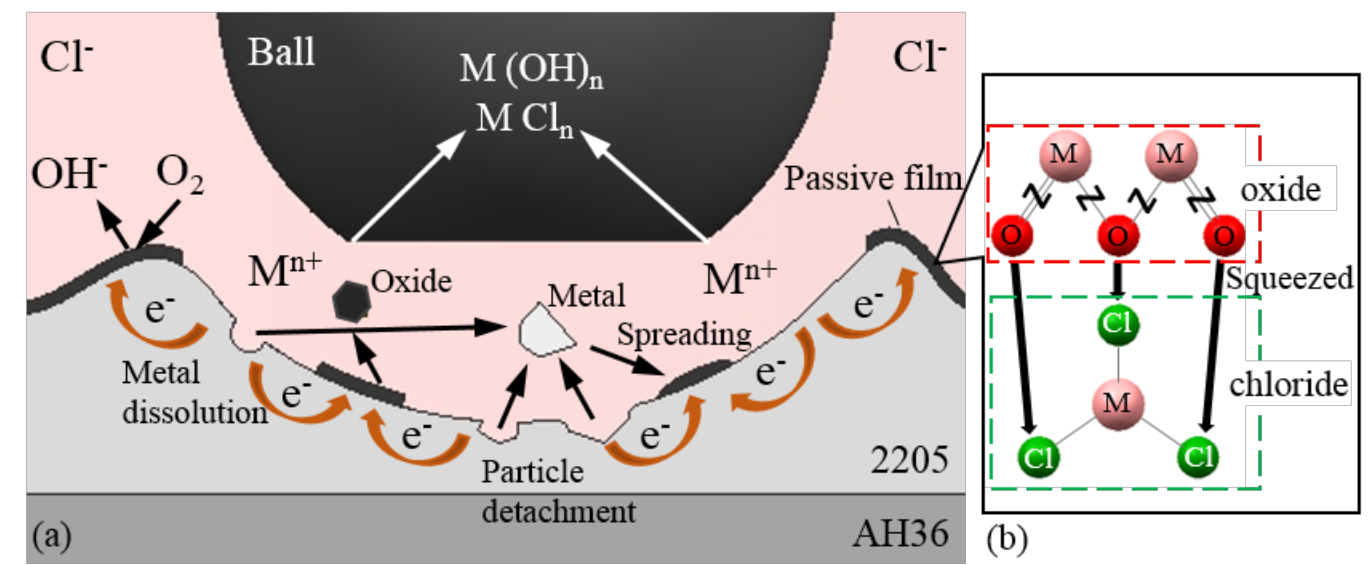

Fig. 17. Schematic illustration of the tribological mechanism in the chloride solution.

Although mechanical wear is dominant during the tribological process in the $3.5 \mathrm{wt}$ \% $\mathrm{NaCl}$ solution, the synergy of wear and corrosion to metals has occurred. This involves several simultaneous processes, including formation and dissolution of passive films, wear-accelerated corrosion and corrosion-accelerated wear $[46,47]$. The schematic illustration of the tribological mechanism in the 
chloride solution is shown in Fig. 17. The metallic wear particles can be detached by the adhesion and abrasion, and eventually ejected from discs as a third body, which is a main part for the degradation of materials in the tribological tests. Alternatively, the wear particles may spread on the wear track of disc or sliding surface of the ball, which cannot contribute to the total wear volume loss. Another way of materials degradation is the electrochemical oxidation of the 2205 layer, which induces the formation of ions dissolution or a passive film on the 2205 layer surface [48]. Although the duplex stainless steel (2205) has excellent corrosion resistance due to the Cr-enriched passive film, the film can mainly be broken by the sliding wear, and the fresh surface with a lower equilibrium potential is exposed in the chloride solution [49]. In addition, the chloride ions $\left(\mathrm{Cl}^{-}\right)$, rich in the 3.5\% $\mathrm{NaCl}$ solution, can be easily adsorbed on the passive film due to their small ionic radius and relatively large electron density. The oxygen atoms $\left(\mathrm{O}^{2-}\right)$ of passive film are squeezed out by the chloride ions $\left(\mathrm{Cl}^{-}\right)$, which then are combined with the cations in the passive film to form a soluble chloride, resulting in the lattice defects and destruction of partial passive film (Fig. 17(b)). This phenomenon can be proved in Fig. 18 that $\mathrm{Cl}$ and $\mathrm{O}$ elements are distributed on the oxidised bands of corrosive worn surfaces.
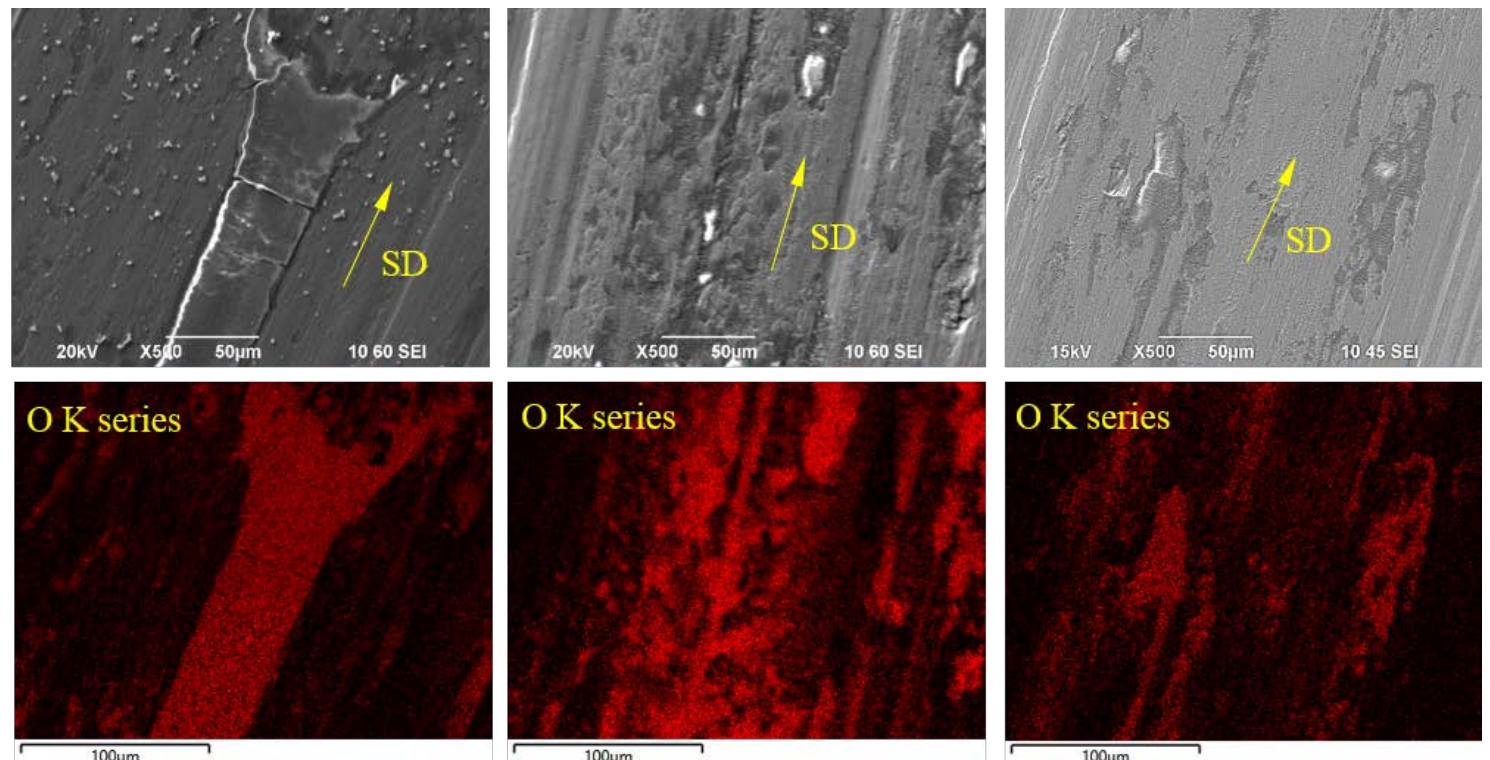

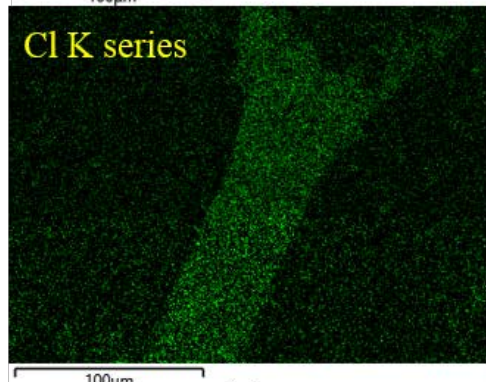

(a)

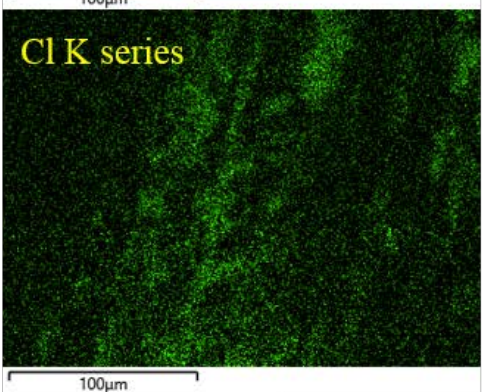

(b)

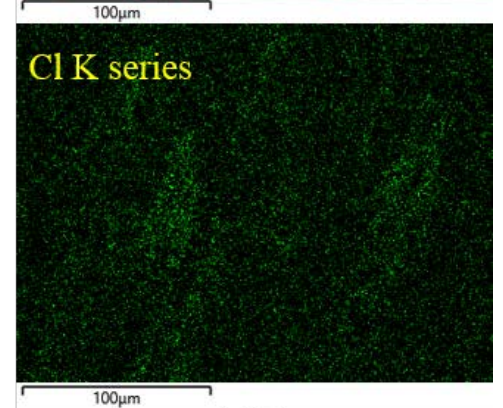

(c)

Fig. 18. SEM images and EDS mappings of the worn surface being tested under different states: (a) asreceived, (b) annealed at $950{ }^{\circ} \mathrm{C}$ and (c) annealed at $1050{ }^{\circ} \mathrm{C}$. 
When a local area of the passive film has been broken by the sliding wear or reaction of chloride ions $\left(\mathrm{Cl}^{-}\right)$, the pitting conditions are achieved and enhanced. According to the electrochemical mechanism, the surrounding passive film acts as the cathode, and the alloying elements, such as $\mathrm{Fe}, \mathrm{Ni}$ and $\mathrm{Cr}$, in the 2205 layer act as the anode [50]:

$$
\mathrm{M} \rightarrow \mathrm{M}^{n+}+n \mathrm{e}^{-}
$$

The released electrons involve in the cathodic reaction, dominated by the dissolution of oxygen occurring on the passive film as expressed:

$$
\mathrm{O}_{2}+2 \mathrm{H}_{2} \mathrm{O}+4 \mathrm{e}^{-} \rightarrow 4 \mathrm{OH}^{-}
$$

The generated hydroxyl ion $\left(\mathrm{OH}^{-}\right)$then can react with alloying elements ion, such as ferrous ion $\left(\mathrm{Fe}^{3+}\right)$. The hydroxide can be obtained, and the process is described as:

$$
\mathrm{M}^{\mathrm{n}+}+\mathrm{n} \mathrm{OH}^{-} \rightarrow \mathrm{M}(\mathrm{OH})_{\mathrm{n}}
$$

For instance, the ferric hydroxide $\left(\mathrm{Fe}(\mathrm{OH})_{3}\right)$, the reddish-brown powder or flocculate, has been observed in the solution after tribological tests [51], as shown in Fig. 14(f). Meanwhile, the rich chloride ions $\left(\mathrm{Cl}^{-}\right)$can also react with alloying elements ion as:

$$
\mathrm{M}^{\mathrm{n}+}+\mathrm{n} \mathrm{Cl}^{-} \rightarrow \mathrm{MCl}_{\mathrm{n}}
$$

In addition, the continual sliding will bring more dissolved oxygen to the disc surface [52], inducing an accelerated cathodic reaction and eventually the more degradation of materials.

\section{Conclusions}

The influences of annealing on the mechanical and tribological coupled behaviours of 2205/AH36 bimetal composite were investigated using the ball-on-disc tribological tests in the $3.5 \% \mathrm{NaCl}$ solution and tensile tests, respectively. The following conclusions can be obtained:

1. The thickness of MBTZ between layers increases significantly with the increase of annealing temperature. The elongation of bimetal composite is sensitively dependent on the annealing temperatures, but the tensile strength exhibits a slight change.

2. The tribological behaviour of the 2205 layer of the bimetal composite is dominated by the mechanical wear in the $3.5 \% \mathrm{NaCl}$ solution. The precipitation of sigma phase, which results in the hardness increase of sliding surfaces after annealing at 850 and $950{ }^{\circ} \mathrm{C}$, improves the wear resistance of duplex stainless steel. 
3. Based on the obtained results of tensile and tribological tests, the composite after annealing at 850 and $950{ }^{\circ} \mathrm{C}$ has the better wear resistance in the chloride solution but worse formability compared to that of other states. Meanwhile, the comprehensive performance of deformability and wear resistance in the chloride solution for the bimetal composite is acceptable after annealing at $1050{ }^{\circ} \mathrm{C}$.

\section{Funding}

This research received financial support from Baosteel-Australia Joint Research and Development Centre (BAJC) under project of BA-16009.

\section{Acknowledgments}

The first author is greatly thankful for the scholarship support (IPTA) from University of Wollongong and scholarship support from China Scholarship Council (CSC). The authors wish to gratefully acknowledge the financial support from Baosteel-Australia Joint Research. The authors wish to gratefully thank Dr. Yi Yan for the help of tensile tests. 


\section{References}

[1] Xu, J., Gao, X., Jiang, Z., Wei, D., and Jiao, S. 2016 Microstructure and hot deformation behaviour of high-carbon steel/low-carbon steel bimetal prepared by centrifugal composite casting The International Journal of Advanced Manufacturing Technology. 86 817-827

[2] Dhib, Z., Guermazi, N., Ktari, A., Gasperini, M., and Haddar, N. 2017 Mechanical bonding properties and interfacial morphologies ofB austenitic stainless steel clad plates Materials Science and Engineering: A. 696 374-386

[3] Khodadad Motarjemi, A., Koc'ak, M., and Ventzke, V. 2002 Mechanical and fracture characterization of a bi-material steel plate International Journal of Pressure Vessels and Piping. 79 181-191

[4] Bataev, I.A., Lazurenko, D.V., Tanaka, S., Hokamoto, K., Bataev, A.A., Guo, Y., and Jorge, A.M. 2017 High cooling rates and metastable phases at the interfaces of explosively welded materials Acta Materialia. 135 277-289

[5] Liu, B.X., Yin, F.X., Dai, X.L., He, J.N., Fang, W., Chen, C.X., and Dong, Y.C. 2017 The tensile behaviors and fracture characteristics of stainless steel clad plates with different interfacial status Materials Science and Engineering: A. 679 172-182

[6] Li, Z., Zhao, J., Jia, F., Zhang, Q., Liang, X., Jiao, S., and Jiang, Z. 2018 Analysis of bending characteristics of bimetal steel composite International Journal of Mechanical Sciences. 148 272-283

[7] Li, Z., Zhao, J., Jia, F., Zhang, Q., Liang, X., Jiao, S., and Jiang, Z. 2018 Numerical and experimental investigation on the forming behaviour of stainless/carbon steel bimetal composite The International Journal of Advanced Manufacturing Technology.

[8] Jin, J.Y. and Hong, S.I. 2014 Effect of heat treatment on tensile deformation characteristics and properties of Al3003/STS439 clad composite Materials Science and Engineering: A. 596 18

[9] Kim, I.-K. and Hong, S.I. 2013 Effect of component layer thickness on the bending behaviors of roll-bonded tri-layered Mg/Al/STS clad composites Materials \& Design. 49 935-944

[10] Lee, J.E., Bae, D.H., Chung, W.S., Kim, K.H., Lee, J.H., and Cho, Y.R. 2007 Effects of annealing on the mechanical and interface properties of stainless steel/aluminum/copper clad-metal sheets Journal of Materials Processing Technology. 187-188 546-549

[11] Akramifard, H.R., Mirzadeh, H., and Parsa, M.H. 2014 Estimating interface bonding strength in clad sheets based on tensile test results Materials \& Design. 64 307-309

[12] Mendes, A., Timokhina, I., Molotnikov, A., Hodgson, P.D., and Lapovok, R. 2017 Role of shear in interface formation of aluminium-steel multilayered composite sheets Materials Science and Engineering: A. 705 142-152

[13] Bina, M.H., Dehghani, F., and Salimi, M. 2013 Effect of heat treatment on bonding interface in explosive welded copper/stainless steel Materials \& Design. 45 504-509

[14] He, W., Ma, J., Zhang, Y., Wen, H., and Liu, Q. 2018 Effect of the annealing process on the microstructure and mechanical properties of multilayered $\mathrm{Zr} / \mathrm{Ti}$ composites Materials Science and Engineering: A. 713 214-222

[15] Macwan, A., Jiang, X.Q., Li, C., and Chen, D.L. 2013 Effect of annealing on interface microstructures and tensile properties of rolled Al/Mg/Al tri-layer clad sheets Materials Science and Engineering: A. $\mathbf{5 8 7}$ 344-351

[16] Zhang, N., Wang, W., Cao, X., and Wu, J. 2015 The effect of annealing on the interface microstructure and mechanical characteristics of AZ31B/AA6061 composite plates fabricated by explosive welding Materials \& Design (1980-2015). 65 1100-1109 
[17] Wang, B., Yao, B., and Han, Z. 2012 Annealing Effect on Wear Resistance of Nanostructured 316L Stainless Steel Subjected to Dynamic Plastic Deformation Journal of Materials Science \& Technology. 28 871-877

[18] Yin, S.B. and Li, D.Y. 2005 Corrosion and corrosive wear of annealed, impact-fractured and slow bending-fractured surface layers of AISI 1045 steel in a 3.5\% NaCl solution Wear. 259 383-390

[19] Mahesh B. Davanageri, N.S., Ravikiran Kadol 2015 Influence of Heat Treatment on Microstructure, Hardness and Wear Behavior of Super Duplex Stainless Steel AISI 2507 American Journal of Materials Science. 5 48-52

[20] Fargas, G., Mestra, A., and Mateo, A. 2013 Effect of sigma phase on the wear behavior of a super duplex stainless steel Wear. 303 584-590

[21] Xia, W., Zhao, J., Wu, H., Jiao, S., and Jiang, Z. 2017 Effects of oil-in-water based nanolubricant containing $\mathrm{TiO} 2$ nanoparticles on the tribological behaviour of oxidised highspeed steel Tribology International. 110 77-85

[22] Wu, H., Zhao, J., Xia, W., Cheng, X., He, A., Yun, J.H., Wang, L., Huang, H., Jiao, S., Huang, L., Zhang, S., and Jiang, Z. 2017 A study of the tribological behaviour of TiO2 nano-additive water-based lubricants Tribology International. 109 398-408

[23] Wu, H., Zhao, J., Cheng, X., Xia, W., He, A., Yun, J.-H., Huang, S., Wang, L., Huang, H., Jiao, S., and Jiang, Z. 2018 Friction and wear characteristics of TiO2 nano-additive waterbased lubricant on ferritic stainless steel Tribology International. 117 24-38

[24] Gholami, M., Hoseinpoor, M., and Moayed, M.H. 2015 A statistical study on the effect of annealing temperature on pitting corrosion resistance of 2205 duplex stainless steel Corrosion Science. 94 156-164

[25] Naghizadeh, M. and Moayed, M.H. 2015 Investigation of the effect of solution annealing temperature on critical pitting temperature of 2205 duplex stainless steel by measuring pit solution chemistry Corrosion Science. 94 179-189

[26] Hoseinpoor, M., Momeni, M., Moayed, M.H., and Davoodi, A. 2014 EIS assessment of critical pitting temperature of 2205 duplex stainless steel in acidified ferric chloride solution Corrosion Science. 80 197-204

[27] Zhao, J., Hun Lee, J., Woo Kim, Y., Jiang, Z., and Lee, C.S. 2013 Enhancing mechanical properties of a low-carbon microalloyed cast steel by controlled heat treatment Materials Science and Engineering: A. 559 427-435

[28] Fargas, G., Anglada, M., and Mateo, A. 2009 Effect of the annealing temperature on the mechanical properties, formability and corrosion resistance of hot-rolled duplex stainless steel Journal of Materials Processing Technology. 209 1770-1782

[29] Chen, G., Li, J.T., Yu, H.L., Su, L.H., Xu, G.M., Pan, J.S., You, T., Zhang, G., Sun, K.M., and He, L.Z. 2016 Investigation on bonding strength of steel/aluminum clad sheet processed by horizontal twin-roll casting, annealing and cold rolling Materials \& Design. 112 263-274

[30] Movahedi, M., Kokabi, A.H., and Seyed Reihani, S.M. 2011 Investigation on the bond strength of Al-1100/St-12 roll bonded sheets, optimization and characterization Materials \& Design. 32 3143-3149

[31] Sun, C.Y., Cong, Y.P., Zhang, Q.D., Fu, M.W., and Li, L. 2018 Element diffusion model with variable coefficient in bimetallic bonding process Journal of Materials Processing Technology. 253 99-108

[32] Chen, Z., Wang, D., Cao, X., Yang, W., and Wang, W. 2018 Influence of multi-pass rolling and subsequent annealing on the interface microstructure and mechanical properties of the explosive welding $\mathrm{Mg} / \mathrm{Al}$ composite plates Materials Science and Engineering: A. 723 97108

[33] Hansen, N. 2004 Hall-Petch relation and boundary strengthening Scripta Materialia. 516 
[34] Xiong, S. and Sun, J. 2018 Sliding wear-induced nano-tribofilm formation from EP/AW agent on copper foil against ferroalloy counterparts under high load Surface and Interface Analysis. 50 1255-1264

[35] Yan, X.D., Sun, J.L., Xiong, S., and Hou, Y.Q. 2017 Insights into the sliding wear behavior of a copper-steel pair with oils containing extreme-pressure additives Wear. 386-387 211-217

[36] Mokhtar, M.O.A. 1982 The effect of hardness on the frictional behaviour of metals Wear. 78 297-304

[37] Chaudhry, V. and Kailas, S.V. 2013 Fretting studies on self-mated stainless steel and chromium carbide coated surfaces under controlled environment conditions Wear. 301 524539

[38] Lu, Z., Cao, Z., Hu, E., Hu, K., and Hu, X. 2019 Preparation and tribological properties of WS2 and WS2/TiO2 nanoparticles Tribology International. 130 308-316

[39] Bao, Y., Sun, J., and Kong, L. 2017 Effects of nano-SiO2 as water-based lubricant additive on surface qualities of strips after hot rolling Tribology International. 114 257-263

[40] Qiu, S., Zhao, H., and Wang, L. 2018 Facile preparation of soluble poly(2-aminothiazole)based composite coating for enhanced corrosion protection in $3.5 \% \mathrm{NaCl}$ solution Surface Topography: Metrology and Properties. 6034007

[41] Wang, Y., Zhao, W., Wu, Y., Liu, G., and Wu, X. 2018 Micro/nano-structures transition and electrochemical response of Ti-6Al-4V alloy in simulated seawater Surface Topography: Metrology and Properties. 6034009

[42] Vieira, A.C., Rocha, L.A., Papageorgiou, N., and Mischler, S. 2012 Mechanical and electrochemical deterioration mechanisms in the tribocorrosion of $\mathrm{Al}$ alloys in $\mathrm{NaCl}$ and in NaNO3 solutions Corrosion Science. 54 26-35

[43] Jiang, Y., Sun, T., Li, J., and Xu, J. 2014 Evaluation of Pitting Behavior on Solution Treated Duplex Stainless Steel UNS S31803 Journal of Materials Science \& Technology. 30 179183

[44] Jeon, S.-H., Kim, S.-T., Kim, S.-Y., Choi, M.-S., and Park, Y.-S. 2013 Effects of SolutionAnnealing Temperature on the Precipitation of Secondary Phases and the Associated Pitting Corrosion Resistance in Hyper Duplex Stainless Steel MATERIALS TRANSACTIONS. 54 1473-1479

[45] Lu, X.-C., Shi, K., Li, S.-Z., and Jiang, X.-X. 1999 Effects of surface deformation on corrosive wear of stainless steel in sulfuric acid solution Wear. 225-229 537-543

[46] Sun, Y. and Rana, V. 2011 Tribocorrosion behaviour of AISI 304 stainless steel in $0.5 \mathrm{M} \mathrm{NaCl}$ solution Mater Chem Phys. 129 138-147

[47] Zhang, T.C., Jiang, X.X., Li, S.Z., and Lu, X.C. 1994 A quantitative estimation of the synergy between corrosion and abrasion Corrosion Science. 36 1953-1962

[48] Landolt, D., Mischler, S., Stemp, M., and Barril, S. 2004 Third body effects and material fluxes in tribocorrosion systems involving a sliding contact Wear. 256 517-524

[49] Li, W.S., Wang, Z.P., Lu, Y., and Yuan, L.H. 2006 Corrosion wear behavior of Al-bronzes in 3.5\% NaCl solution Journal of Materials Engineering and Performance. 15 102-110

[50] Zhang, Y., Yin, X., Wang, J., and Yan, F. 2014 Influence of microstructure evolution on tribocorrosion of 304SS in artificial seawater Corrosion Science. 88 423-433

[51] Zhang, Y., Yin, X., Wang, J., and Yan, F. 2014 Influence of potentials on the tribocorrosion behavior of 304SS in artificial seawater RSC Advances. 4 55752-55759

[52] Melchers, R.E. 2003 Effect on marine immersion corrosion of carbon content of low alloy steels Corrosion Science. 45 2609-2625 